\title{
27 Men's views of antidepressant treatment for depression, and their 28 implications for community pharmacy practice.
}

\section{Introduction:}

Community pharmacy as a profession, is striving to provide better support for people experiencing mental health problems such as depression ${ }^{1}$. Depression is the fifth leading cause of global disability accounting for $4.2 \%$ of global years lived with a disability ${ }^{2}$. It can worsen treatment outcomes for co-morbid conditions ${ }^{3}$ and is a risk factor for heart disease ${ }^{4,5}$, suicide $^{6}$ and alcohol abuse ${ }^{7}$.

Men with depression have worse mortality outcomes compared to women with depression ${ }^{8,9}$. This is somewhat explained by differences in their navigation of depression. Some men mask symptoms ${ }^{10}$ and engage in recovery hindering behaviors such as delayed help-seeking ${ }^{11-13}$ and alcohol abuse ${ }^{14}$. Many men have poorer socialsupport networks, which has been linked to hindered mental health recovery ${ }^{15}$. Hegemonic masculinity is a concept that can partially explain these findings. It is a pattern of practices, mainly enacted by men, to demonstrate or protect one's masculine status ${ }^{16}$. In western societies stoicism, strength, control, and restricted emotionality are traits typically characteristic of hegemonic masculinity ${ }^{17}$, and though men should not be seen as a homogenous group, the concept of hegemonic masculinity might help orientate healthcare professionals to relevant mental health phenomena such as self-stigmatisation in response to a threat to gender status ${ }^{13,18,19}$. For some men, reconstruction of one's masculinity is part of depression recovery ${ }^{20}$. However, hegemonic masculinity has nuanced meanings across different individuals, cultures, and contexts ${ }^{21,22}$.

Community pharmacists can support men treating depression, particularly those taking antidepressants. They routinely interact with these patients, have expertise to address medicine related issues and have good mental health literacy ${ }^{23-25}$. Optimally utilising community pharmacists could also alleviate pressures elsewhere in the healthcare system ${ }^{1}$. Yet men underutilise these professionals ${ }^{26,27}$, and there is little knowledge about what men taking antidepressants see as the role of the community pharmacist in their treatment journey, or how community pharmacists can best support them. predominantly focus upon medication counselling, as opposed to psychosocial discussions ${ }^{28}$. Both community 
pharmacists and patients consider the community pharmacist's contributions in depression care to be around medication safety and supply, and providing information, particularly around adverse drug reactions ${ }^{23,29}$. Community pharmacists typically spend more time counselling patients who are newly prescribed antidepressants compared to those collecting antidepressant refills, and do not tend to proactively counsel these refill patients ${ }^{24,30,31}$. Yet antidepressant users desire community pharmacists to proactively provide follow-up care $^{32}$. These patients want to capitalise on community pharmacist knowledge but can struggle to know what to $\mathrm{ask}^{32}$. A suggestion from patients taking antidepressants in a Canadian study was that the community pharmacist should initiate regular discussions so that important topics could be discussed naturally ${ }^{24}$.

Good patient-community pharmacist relations, patient centred care and progressive patient trust can facilitate pharmacy depression interventions ${ }^{33-36}$ and the perception of community pharmacy as a 'safe space' ${ }^{33,37}$. Multifaceted pharmacy interventions for depression have been more successful than just educational interventions ${ }^{38}$, although the results only demonstrated improved antidepressant adherence, not clinical outcomes. These studies predominantly recruited females, with a median of $70 \%$ female participants, therefore findings are not male specific. Interventions that are sensitive to men and action-focused could be more beneficial to men with depression ${ }^{39,40}$, yet it is unknown what this means for a community pharmacy context.

A better understanding of how community pharmacists can support men taking antidepressants is important because, although antidepressants are an effective option for treating major depression ${ }^{41}$, there are barriers to their practical application. These include adverse drug reactions ${ }^{42,43}$, including male-specific complaints (e.g. erectile dysfunction), poor adherence ${ }^{44-46}$, and stigma ${ }^{42,43,47}$. Understanding such phenomena has improved patient outcomes in depression ${ }^{48-50}$.

Some antidepressant users question the bio-chemical explanations of their condition ${ }^{48}$, and the validity of pharmacological treatment ${ }^{51}$. This results in the creation of a moral framework to legitimise their treatment choice and continuation ${ }^{52}$. Taking antidepressants can involve both a decision and meaning making process ${ }^{53}$. For example participants experience conflict over 'duty to be well' versus 'taking the easy way out'. How one feels about antidepressants can be a constant re-evaluation process ${ }^{53}$. There is limited knowledge about men's views of taking antidepressants. Studies suggest findings are similar to non-gender specific studies, although hegemonic masculinity is influential for some aspects ${ }^{20,54}$. Some men felt taking antidepressants compromised 
To explore men's views around antidepressant treatment, including the influences of hegemonic masculinity, and consider their perceptions of community pharmacists' role in their antidepressant treatment. The secondary aim of this study is to consider what these findings mean for community pharmacy practice.

\section{Method:}

This study has a qualitative study design. It has been designed and reported in line with Standards for Reporting Qualitative Research (SRQR) guidelines ${ }^{57}$. The method for data collection was individual semi-structured, audio recorded interviews. There is an underlying assumption in this study that realities are multiple and socially constructed in line with a constructivist research paradigm.

A brief interview schedule was developed to address identified gaps in the literature. Key topics were around men's views of antidepressants, experiences of the community pharmacy, insights into unmet care needs and potential improvements (see appendix 1). The interview schedule was piloted prior to use. This involved internal testing with two researchers experienced in qualitative methods, and field-testing with three males, two of whom had past experience of taking antidepressants to treat depression. Based on the piloting some changes were made, for example the word 'intervention' was replaced with 'service' and a question was added to ensure a shared understanding between participants and interviewer on the definition of 'community pharmacist'. A standardised opening question was used to establish an understanding on participant's antidepressant history, and to ease participant into the interview.

Eligible participants were males, fluent in English, aged 18-65 years and prescribed antidepressants to treat depression, including those treating depression with anxiety. Males under 18 years were excluded since this age range has unique antidepressant prescribing guidance due to different pharmacokinetics and treatment risk ${ }^{43}$. Those over 65 years were excluded since depression in the elderly can be influenced by factors related to ageing 58. Participants with diagnosed schizophrenia, psychosis or dementia were excluded.

Convenience sampling was used for recruitment. Recruitment (and interviews) occurred from August 2017November 2018. Recruitment occurred via poster recruitment either at a United Kingdom (UK) University (two participants), or at five participating UK community pharmacies (three participants), or by the community pharmacists in these branches identifying and approaching eligible participants who presented in the pharmacy (nine participants). Recruitment discussions occurred in private areas. For all participants a subsequent 
discussion was held with a researcher prior to participation to confirm they met inclusion criteria and they understood the study. Recruitment occurred till data saturation, which was determined when the last two interviews produced no new themes. Information power (see Malterud et al ${ }^{59}$ ) was also considered to 'sense check' if data saturation was likely to have occurred. Fourteen participants were recruited in total. A relatively small number of participants could reach data saturation because the study has a fairly narrow aim, and participants hold specific knowledge and experiences relevant for this aim. Fourteen participants seemed reasonable for data saturation to have occurred and passed the 'sense-check'. The ages of recruited participants ranged from 26-61 years old. The mean age was 49 years.

Interviews ranged from $39-71$ minutes. The mean duration was 56 minutes. All interviews were conducted by the same female researcher (SB) who was a qualified pharmacist. This researcher had received extensive training on interviewing prior to conducting the interviews. The participants were briefed that the interviewer was a pharmacist, however she was introduced to participants as a 'researcher'.

Interviews were transcribed verbatim, and analysed using thematic analysis (e.g. see Braun and Clarke 2006 ${ }^{60}$ ). NVivo12 was used for analysis. The codes were predominantly coded inductively, however 'hegemonic masculinity' was coded deductively. Initially, a long list of themes were developed by SB, who organised themes in the list into a candidate set of super-ordinate categories and sub-themes. A technique described by Ziebland and McPherson ${ }^{61}$ facilitated this process (the one sheet of paper technique). Authors met to discuss coding and themes, and to explore alternative interpretations. The research team comprised of a community pharmacist, a social pharmacy professor, and a male researcher with personal experience of depression.

This qualitative study is part of a wider study about developing a complex intervention. Participants were aware about the nature of this study at the time of interview. Eight participants expressed interest in further involvement. These eight also partook in member checking, where the researcher invited further contributions on interviews and the preliminary analysis.

\section{Ethics Approval:}

UK Research Ethics Committee and University of Nottingham granted ethical approval [Ref: 17/EM/0264]. All participants signed a consent form and were offered a $£ 10$ voucher for participation. Pseudonyms were used. Participants agreed their confidentiality could be breached to access a professional (e.g. G.P) if the research team had safeguarding concerns. 
139 Results:

140 Table 1 highlights participant demographics. Fourteen participants were recruited. Nine out of fourteen

141 participants had used antidepressants for more than one year, five for less than one year, and of those five, three

142 had prior episodes of depression treated with antidepressants. The men had a mix of employment and

143 relationship status, yet were predominantly aged 40-60 years and Caucasian. 


\begin{tabular}{|c|c|c|c|c|c|c|c|c|}
\hline 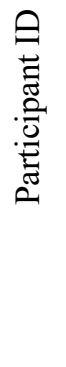 & 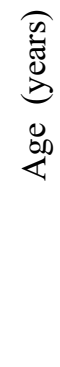 & 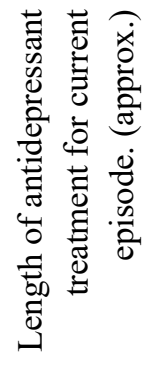 & 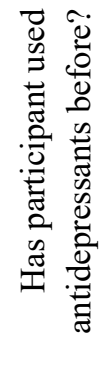 & 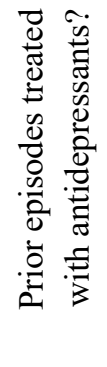 & 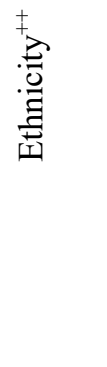 & 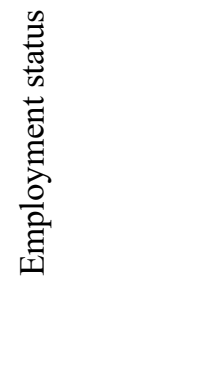 & 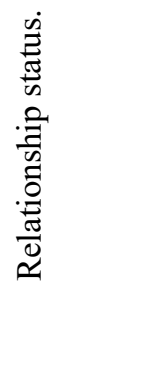 & 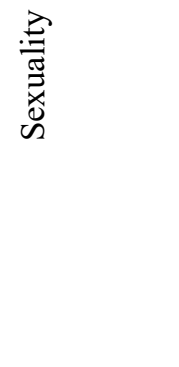 \\
\hline P1 & 59 & 8 months & No* & No * & White & Unemployed & $\begin{array}{l}\text { Divorced } \\
\text { /Single }\end{array}$ & Heterosexual \\
\hline P2 & 58 & 20 years & Yes & $\mathrm{No}+$ & White & Unemployed & $\begin{array}{l}\text { Divorced } \\
\text { /Single }\end{array}$ & Heterosexual \\
\hline P3 & 46 & 2.5 years & Yes & Yes & White & Unemployed & $\begin{array}{l}\text { Divorced } \\
\text { /unknown }\end{array}$ & Heterosexual \\
\hline P4 & 61 & 11 months & Yes & Yes & White & Retired & Married & Heterosexual \\
\hline P5 & 41 & 6-7 years & Yes & Yes & White & Unemployed & $\begin{array}{l}\text { Divorced } \\
\text { /unknown }\end{array}$ & Heterosexual \\
\hline P6 & 40 & 11 months & Yes & Yes & White & $\begin{array}{l}\text { Unknown- } \\
\text { Paternity } \\
\text { leave? }\end{array}$ & Married & Heterosexual \\
\hline P7 & 41 & $10-15$ years & Yes & $\mathrm{No}+$ & White & Employed & Unknown & Homosexual \\
\hline P8 & 43 & $8-9$ years & No & N/A & White & Employed & Married & Heterosexual \\
\hline P9 & 59 & 6-7 years & No & N/A & White & Employed & Married & Heterosexual \\
\hline P10 & 59 & $4-5$ years & Yes & $\mathrm{No}+$ & White & Employed & Married & Heterosexual \\
\hline P11 & 51 & 1-2 weeks & No & N/A & White & Unemployed & Single & Heterosexual \\
\hline P12 & 60 & $4-5$ months & Yes & Yes & White & Employed & Married & Heterosexual \\
\hline P13 & 40 & 1.5 years & Yes & Yes & White & Self-employed & Married & Heterosexual \\
\hline P14 & 26 & 2 years & No & N/A & $\begin{array}{l}\text { White } \\
\text { (Other) }\end{array}$ & Employed & Married & Heterosexual \\
\hline
\end{tabular}
ethnic groups recommended for use by England and Wales government ${ }^{62}$. 


\section{Antidepressant's attributions to benefits.}

All of the men in this study identified an improvement in their functioning when taking their current antidepressants.

P7:Those really dark, horrible, awful thoughts. I have considerably less when taking the medication.

Yet some were uncertain as to what extent these improvements were attributable to antidepressants.

P1: I would like to think, and I'm sure it is, that the tablets must've been kicking in that gave me the motivation to go out and go running, but I don't know you see that's it. I don't know if it was.

Most men tolerated this uncertainty. It however became problematic when they were considering stopping.

Some men stopped antidepressants to ascertain if they could function without them.

Researcher: What was your reasoning for weaning yourself off?

P10: Because I thought that... I'm not a great fan of taking medication that is not necessary and the only way to know if it is not necessary...

Many men had unsuccessful withdrawal attempts. They spoke of suddenly feeling "flat" or "awful" and feeling they must restart antidepressants. They were then unsure how to explain their unsuccessful withdrawals, potentially attributing it to placebo effects. These experiences made men more cautious about stopping antidepressants, yet they still reported desiring to do so at some point.

P8: I never know if I can wean myself off or whether I should stay on the level I am on, but to me I have tried to reduce the amount before and I felt shaky and nervous, whether that is placebo effect or not I do not know.

Some men sought a discussion with a healthcare professional to ascertain if the dose and/or continuation of antidepressants was appropriate. If they had not had such a review, this led to feelings such as being "lost in the system", "drifting along" or being on their own. 


\section{Views of community pharmacists' role influences engagement.}

Medication supply was seen by participants as community pharmacists' key role in their depression treatment. Most accounts highlighted community pharmacists' dispensing role, and occasions when community pharmacists had taken an action to ensure participants had medicines, e.g. an emergency supply. There were some accounts of community pharmacists counselling and supporting participants, which in turn increased a participant's confidence in their treatment.

P11: (the pharmacist) said you will probably see some improvements after a few weeks [...] If somebody encourages me, they say this will help you; people who know what they are talking about like the pharmacist and the doctor, I do listen to people.

Yet mainly interactions with community pharmacists were sparse and most participants had not sought-out advice from community pharmacists.

P10: They are just basically a dispenser and it is usually the assistant that hands it out. The pharmacist you tend never to talk to.

Researcher: Ah-huh.

P10: I have never sought to talk to the pharmacist about it.

These participants did not express dissatisfaction with community pharmacists' input in their treatment journey; most were not expecting more. Yet two participants who had a vocational association with the profession felt more support could have been offered from community pharmacists.

P14: It just would have felt nice that someone would have concerned themselves with me [...] It seemed like a very closed interaction.

Some reflected how not understanding the role of the community pharmacist stopped them from discussing concerns because they were not aware of the option. This was confounded by how they were feeling in their depressed state, being inclined to keep things in, particularly when they had not previously established a clinical relationship with the community pharmacist.

P6: It would be really difficult to convince me to have a chat with the pharmacist. Partly because I did not understand their role, partly because of the mind-set at that point in time. I 
guess I have always had a good relationship with my G.P and I did not with my pharmacist back then.

The physical environment and staff resources were also barriers to sensitive discussions.

P13: There is a till and you talk to someone and everyone's there [...] you can't really say anything discreetly [...] also I would want to know that they have the time. If I can see that there is 10 people in the queue I am not going to feel like I can have a 10 minute conversation with them.

If community pharmacists proactively suggested interactions it was felt this could facilitate engagement, yet participants would need to know community pharmacists had appropriate expertise, resources, and that interacting with the community pharmacists was in line with collaborative care. One participant (P2) linked interacting with community pharmacists as "going behind the G.P's back" believing instead their role in the U.K's National Health Service (NHS) model of care system was to supply medication. Alternatively another participant (P4) referenced how the pharmacy was being advertised as a healthcare resource to utilise and used that as a justification for engagement.

\section{Reflection of support and information needs.}

Participants spoke about needs to normalise taking antidepressants. This could be done by the pharmacist's communication styles.

P13: I think they can help by almost not reacting, certainly not reacting negatively, and treating you normally and cheerfully, I guess those sorts of approaches means it is not made a big thing of it normalises it a little bit.

It could also be done through the information provided, for example participants wanted to know if their dose was high or low, and therefore what this said about their condition. They also wanted to understand any adverse drug reactions that would be likely based on their dose, and support on how to interpret information from the Patient Information Leaflet and the internet based on their dose. 

useful.

Participants felt the accessibility of the community pharmacists, and their knowledge and skill set, meant they could help them with these medication support and information needs. Participants also reflected upon struggles with coming off antidepressants, and mismatched expectations of treatment duration, some initially viewing it as a 'quick fix'.

Participants were asked about service ideas or support pharmacies could offer. Most struggled to suggest developed ideas. Predominantly, ideas focused around improving healthcare access such as hosting psychological therapy services, or peer support groups at the pharmacy. Alternatively community pharmacists could organise patient's access to these services. The reasoning behind why these ideas were suggested was linked to how easily extra steps to engagement became barriers.

P14: I was signposted to a counselling service or a therapy service, and I had to phone them, book an appointment, where as if a doctor or a pharmacist has the opportunity to just do that for me then it would have joined it up better.

Researcher: So what was the issue with you having to speak to them and call up?

P14: You are looking for excuses not to do things.

There was a desire for community pharmacists to be another point of contact, being able to triage men who are struggling, and this was linked to reflections that asking for help could be difficult. Some mentioned gender sensitive training or services, as there was an awareness that men could perceive threats to masculinity due to depression. However, equally men did not want to be patronised or stereotyped.

\section{Hegemonic masculinity and taking antidepressants.}

Antidepressants causing benefits was, for some, an assertion that they had not solved their depression themselves. For them it symbolised a weakness, failure, madness, or dependence upon something. 
These feelings could be problematic with ones masculinity. a male.

Yet taking antidepressants could be seen as a logical approach, symbolic of taking ownership to solve problems. One participant symbolised his masculinity by positioning men not taking prescribed antidepressants as not being masculine.

P3: I was going to say 'a big...big girls blouse' well yes stop being a big girls blouse, and basically pull your finger out and take it.

Influences of masculinity could cause challenges in healthcare interactions. When P9 is asked about his views about being approached by the community pharmacist to discuss medication he perceives a potential threat to his masculinity.

P9: I don't know. I honestly could not say because is there a maybe a little bit of stigma attached 'oh this bloke has got antidepressants'.

Some men were not used to opening up about their feelings. This caused barriers to discussions around depression treatment and concerns.

Researcher: Linked to your concerns [about taking antidepressants], were those concerns you felt that you could ask as a question?

P6: To the pharmacist?

Researcher: To anyone.

P6: Yeah.... no.

Researcher: Ah-huh.

P6: Definitely.

Researcher: Can you describe why that was?

P6: I suspect it was partly a gender thing, although I do not want to generalise too much. I did feel quite isolated as a man and that men do not really talk about it. 
At the point of first being prescribed antidepressants, the men spoke of being focused on obtaining a solution to their depression. Underlying this focus was a desperation; a feeling they had no choice but to seek treatment. The men explained that their impaired cognitive state hindered approaches such as gathering information, deliberation, or exploring concerns relating to antidepressants.

Researcher: You have not used them before, was there any concerns about taking them? P5: I did not even think about it. Researcher: Did not think about it. Ah-huh. P5: Because I did not... I did not feel normal at all.

Exploring concerns could also be seen as counterintuitive to obtaining a solution.

P2: I think I was of a state where I was like just give me something. I am not going to start quibbling.

One participant presented an analogy to illustrate difficulties in mind-set when one has impaired mental health. He suggests that, when depressed, one may not make rational, engaged choices; yet when in a healthier mind one may have more purposeful engagement with treatment once that treatment has shown to facilitate recovery.

P3: Well when you are depressed it is a bit like being dehydrated the last thing you want to do is drink water when you are dehydrated, but then when you start drinking the water you get the taste for it and then you force it down, eventually start to get thirsty and you want to drink water and then obviously become rehydrated again, it is kind of similar.

Participants also spoke of frustration when their initial strategy to take the antidepressants did not result in quick recovery. This led to feelings of being alone, frustration with the prescriber, the manufacturers of the medicine, and disbelief in the treatment strategy. Few felt able to express these concerns, instead presenting a front.

P12: The thing with antidepressants is they're not quick enough...Every time they said to me 'are you going to kill yourself?' So I thought I'll say no but it's a bit of a cop-out because you go around the corner and you think, God I feel awful today. I really feel horrible today, and I'll wait till everybody's gone to work and then I'll do what I do. 


\section{Discussion:}

304 This is the first study to explore the community pharmacist's role in antidepressant treatment from the perspective of men with depression. There is seemingly a disconnect between what participants in this study view as the community pharmacist's role within their care, and what the professional body for pharmacy visualises the community pharmacist's role to be. Professional bodies advocate for a greater role for community pharmacists in mental health ${ }^{1}$. Yet the findings of this study showed most participants viewed the community pharmacist's role to be around safely dispensing their medication, and accounts of the community pharmacist's involvement in their care were sparse; a finding also found in studies looking at both genders ${ }^{63,64}$. Participants did not express dissatisfaction with this, except two participants who had a vocational association with the profession.

To understand this disconnect, and how it might be changed, key themes are discussed. The first being men's cognitive state when first prescribed antidepressants. This study is the first study to give salient voice to men's reflections on how their condition impaired their gathering of information, and a decision making process, when starting antidepressants. The men were focused upon obtaining a solution to their depression. They were unlikely to have given cognitive space to explore concerns or beliefs, and were not seeking to deliberate and gather information. In some cases such an approach was likened to being a barrier to obtaining a solution [starting and/or obtaining antidepressants]. Depression can hinder ones decision making ability, particularly by impairing deliberation and appreciation of information ${ }^{65}$. Many men suffering from depression present to healthcare professionals at the point of desperation and despair ${ }^{10}$. This pattern has been linked to hegemonic masculinity, where men advocate stoicism or solving depression themselves first, and delay help-seeking until a point of despair ${ }^{13,66}$. Despair as a phenomenon has been connected to impaired engagement and information gathering in patients with mental illness ${ }^{67}$. Participants also spoke about how they were inclined to keep concerns in check, and were not used to discussing their mental health. Previous studies have found that men may be less articulate than women when depressed ${ }^{14,68,69}$.

Yet this study did find that the men, when reflecting, highlighted unmet information and support needs. Key initial support and information needs were predominantly around normalising the condition and contextualising their treatment. Other studies have shown men can self-stigmatise for taking antidepressants ${ }^{70,71}$ and may undergo a meaning making process, involving cognitive realignment on what it means to take antidepressants. This study supports this finding and adds that participants can go through a meaning making process upon what 
their prescribed dose means in terms of their depression, and how it relates to others.

333 Another key finding, also shown in mixed-sex studies ${ }^{72}$, was the struggle the participants expressed with 334 knowing when to stop antidepressants. This finding is linked to uncertainty on the extent antidepressants were causing noticed benefits, and initial unrealistic views of treatment duration. These initial unrealistic views could go unchallenged as men, due to their cognitive state, were not seeking to verify beliefs.

Men spoke about barriers to community pharmacy interactions. Some barriers found in this study have already been shown in other literature, such as the physical set up of a pharmacy causing privacy concerns ${ }^{36}$ which was linked to stigma, and concern of antidepressants signifying meaning to others.

An interesting finding was the need for participants to know as a requisite for engagement, that they were interacting within the community pharmacists' scope of practice and competency, and as part of the wider NHS strategy of care. This makes the finding that participants saw the role of the community pharmacists predominantly as a supplier of medicines all the more pertinent, creating a barrier for unsolicited engagement. Particularly concerning was that participants could liken turning to community pharmacists for advice as "going behind the G.P's back".

\section{Implications for Community Pharmacy Practice:}

347 Some men may be unlikely to proactively engage with the community pharmacist in discussions around depression and treatments. Such an approach is not in line with their recovery strategy. Instead pharmacy could consider ways to facilitate engagement. Men could be educated that discussions around antidepressants, and wider holistic care is within community pharmacists' scope of practice and expertise. It may be particularly important for pharmacy as a profession to seek ways to implement closer collaborative care with other mental health providers. In the UK community pharmacy access to a patient's clinical records is restricted. They can access a patient's NHS Summary Care Record, yet the accessible information is clinically limited ${ }^{73}$, and collaborative working models between community pharmacists remains minimal ${ }^{73}$ a finding also found in other countries ${ }^{74,75}$. Researchers have recommended that community pharmacy interventions incorporate strategies to link with prescribers ${ }^{63,76}$. This current study strengthens this recommendation, but also further expands on it; both the collaborative system, and patients understanding of it need improving. Relevant healthcare professionals should help patients understand collaborative care behaviour, and improve patient's perception of a community pharmacists' role within a collaborative care model. 
Community pharmacists should encourage patients to explore their concerns and beliefs. This is particularly important since patient beliefs around antidepressants influence adherence ${ }^{77}$. Community pharmacists may need to help participants normalise their condition and treatment. This may include giving information on dose ranges and if their dose is normal. Community pharmacists should ensure patients are aware of potential side effects of antidepressants when newly starting, or when having a dose change. Literature shows minimal evidence of negative impact of such discussions ${ }^{78}$. Community pharmacists could reiterate that antidepressants should not be considered as a "quick fix", and ask monitoring questions throughout treatment, particularly as some men feel "lost in the system" when stabilised on the medication. In particular this study found a need for staggered support over time, and that is where the accessibility of community pharmacists could be particularly useful, a finding supported by other literature ${ }^{79}{ }^{80}$. Some participants had unsuccessful attempts at stopping antidepressants and attributed this to placebo effects. An awareness that patients can hold such views could help pharmacy practice. Particularly as it is possible such experiences could be linked to withdrawal symptoms, which can vary in severity and duration between patients ${ }^{81}$. Patients should be educated on withdrawal and managed appropriately.

While this study did not assess adherence it is worth noting all the men were currently taking their antidepressants and either felt antidepressants improved their mood, or perceived a need to be on antidepressants. Literature has shown that perceived need for antidepressants can increase adherence, although only if this outweighs concern on the medication ${ }^{82}$. Overall it is important for community pharmacists to explore patient's views on antidepressant need, highlight the potential benefits of the medication, while also exploring any concerns as highlighted above.

These findings come from male participants, but not all findings are gender specific. It seems that antidepressants could challenge masculinity, yet not all men will experience this. Care should be taken not to patronise or stereotype men as this could be detrimental ${ }^{40,83}$. Community pharmacists should also be aware that men when depressed may put on a front, as a strategy to keep concerns in check, and this could be a barrier to communication.

Translation of these recommendations into routine practice will need careful planning and support from leaders of the profession as some barriers such as time ${ }^{23,29,84}$, lack of pharmacists confidence in talking to those with depression ${ }^{84-87}$, and lack of collaboration with physicians ${ }^{23,84}$ need addressing at both an individual and organizational level ${ }^{76}$. 
$390 \quad$ Limitations of study:

391 This was a small scale study. Based on the last two interviews producing no new themes it can be said data saturation was reached, however participants are predominantly Caucasians aged 40-60 years. Therefore it is not clear how generalizable results are. Further studies focusing on different ethnicities, and those aged 18-25 years would be beneficial.

The researcher was female and a pharmacist which could have influenced the responses the men gave. Also most participants were recruited by a community pharmacist and this again could have influenced responses men gave on topics of community pharmacy. Yet care was given to create rapport and encourage the men to give full responses, which may have addressed this.

Another issue from recruitment via the community pharmacist is that pharmacists may have recruited those they knew. However the pharmacist recruiters confirmed they recruited a mix of participants they knew, and those they did not. Also having varied recruitment routes (e.g. posters) could have decreased this potential bias risk.

Most men gave reflective accounts, and this could be subject to recall bias. This study also reported participants' perceptions for how community pharmacists could improve their care and these may not be beneficial in practice. Some men suggested intervention ideas, yet ideas presented lacked depth and/or explanation of active components. This is expected since the method in this study facilitates gathering of ideas, but not a systematic and rigorous approach for intervention development, and results should be interpreted within this context. Further work around developing gender sensitive pharmacy services using appropriate methods would be useful.

\section{Conclusion:}

Some men, particularly those that adhere to hegemonic masculinity may not seek out consultations with community pharmacists around their condition or treatment. It is known hegemonic masculinity can delay men seeking treatment until a point of desperation. This study finds that in this state, they are not giving cognitive space to explore their information needs nor their underlying views around antidepressants. Most men had not sought advice from the community pharmacist. Medication supply was seen as the principal role of the community pharmacist in their care. 

around their antidepressants and wider support. If men view such interactions as within community pharmacists' scope of practice and expertise, part of a collaborative healthcare system, and not threatening to their masculinity, then these engagements are more likely to be acceptable to men. Such interactions can be beneficial at first prescription and also throughout treatment, and discontinuation.

Appendix.

Appendix 1: Interview guide used in semi-structured interviews.

\begin{tabular}{|c|c|c|}
\hline Purpose of question & Question & $\begin{array}{l}\text { Question } \\
\text { Path: }\end{array}$ \\
\hline $\begin{array}{l}\text { Opening/ Introductory } \\
\text { question: }\end{array}$ & How long have you been taking your (current) antidepressant? & \\
\hline Second: & Was this the first time you used antidepressant medication? & \\
\hline General questions: & $\begin{array}{l}\text { When you had your new prescription, did you remember having } \\
\text { any concerns? }\end{array}$ & \\
\hline Follow up/Probe: & $\begin{array}{l}\text { What were they, can you describe further? What specifically } \\
\text { concerned you? Etc. } \\
\text { Or if 'no' - ask about did they remember having a need for further } \\
\text { information? }\end{array}$ & \\
\hline General questions: & $\begin{array}{l}\text { Did you ask any questions? } \\
\text { (or if relevant:) speak about these concerns? }\end{array}$ & $\begin{array}{l}\text { If } \\
\text { relevant }\end{array}$ \\
\hline Follow up/Probe: & $\begin{array}{l}\text { Who did you ask/speak to? What influenced your decision to ask } \\
\text { this person? }\end{array}$ & If 'yes' \\
\hline General questions: & Did you have any concerns that could be easily asked as a question? & \\
\hline Follow up/Probe: & $\begin{array}{l}\text { Can you give examples/What were they, can you describe further? } \\
\text { What specifically makes them easy to ask? Etc. }\end{array}$ & \\
\hline General questions: & Did you have any concerns that were not easily asked as a question? & If 'yes' \\
\hline General questions: & $\begin{array}{l}\text { Can you describe further? What are the challenges to ask these in a } \\
\text { question form? What makes them not easily asked as a question? }\end{array}$ & \\
\hline General questions: & $\begin{array}{l}\text { When you had your new prescription, did you remember having } \\
\text { any need for further support? }\end{array}$ & \\
\hline
\end{tabular}




\section{References:}

1. Royal_Pharmaceutical_Society_England. No health without mental health: How can pharmacy support people with mental health problems?

https://www.rpharms.com/Portals/0/Documents/RPS\%20mental\%20health\%20r oundtable\%20report\%20June\%202018_FINAL.pdf?ver=2018-06-04-100634-577 2018. Accessed: 15.06 .19

2. Vos $\mathrm{T}$, Abajobir AA, Abate $\mathrm{KH}$, et al. Global, regional, and national incidence, prevalence, and years lived with disability for 328 diseases and injuries for 195 countries, 1990-2013;2016: a systematic analysis for the Global Burden of Disease Study 2016. The Lancet. 2017;390:1211-1259.

3. Rayner L, Price A, Evans A, Valsraj K, Higginson IJ, Hotopf M. Antidepressants for depression in physically ill people. Cochrane Database of Syst Rev. 2010.

4. Van der Kooy K, van Hout H, Marwijk H, Marten H, Stehouwer C, Beekman A. Depression and the risk for cardiovascular diseases: systematic review and meta analysis. Int J Geriatr Psychiatry. 2007;22:613-626.

5. Carney RM, Freedland KE. Depression and coronary heart disease. Nat Rev Cardiol. 2016;14:145.

6. Möller-Leimkühler AM. The gender gap in suicide and premature death or: why are men so vulnerable? Eur Arch Psychiatry Clin Neurosci. 2003;253:1-8.

7. Sullivan LE, Fiellin DA, O'Connor PG. The prevalence and impact of alcohol problems in major depression: A systematic review. Am J Med. 2005;118:330341.

8. Cuijpers $P$, Vogelzangs $N$, Twisk J, Kleiboer A, Li J, Penninx BW. Is excess mortality higher in depressed men than in depressed women? A meta-analytic comparison. J Affect Disord. 2014;161:47-54.

9. Gilman SE, Sucha E, Kingsbury M, Horton NJ, Murphy JM, Colman I. Depression and mortality in a longitudinal study: 1952-2011. CMAJ. 2017;189:E1304-E1310.

10. Brownhill $S$, Wilhelm $K$, Barclay $L$, Schmied V. 'Big Build': Hidden Depression in Men. Aust N Z J Psychiatry. 2005;39:921-931.

11. Galdas $P M$, Cheater $F$, Marshall $P$. Men and health help-seeking behaviour: literature review. J Adv Nurs. 2005;49:616-623.

12. Yousaf $O$, Grunfeld EA, Hunter MS. A systematic review of the factors associated with delays in medical and psychological help-seeking among men. Health Psychol Rev. 2015;9:264-276.

13. Seidler ZE, Dawes AJ, Rice SM, Oliffe JL, Dhillon HM. The role of masculinity in men's help-seeking for depression: A systematic review. Clin Psychol Rev. 2016;49:106-118.

14. Ramirez JL, Badger TA. Men Navigating Inward and Outward Through Depression. Arch Psychiatr Nurs. 2014;28:21-28.

15. Conrad D, White AK. Promoting men's mental health: Radcliffe Publishing; 2010.

16. Connell RW, Messerschmidt JW. Hegemonic masculinity: Rethinking the concept. Gend Soc. 2005;19:829-859.

17. Courtenay WH. Constructions of masculinity and their influence on men's wellbeing: a theory of gender and health. Soc Sci Med. 2000;50:1385-1401.

18. Michniewicz KS, Bosson JK, Lenes JG, Chen JI. Gender-atypical mental illness as male gender threat. Am. J. Mens Health 2016;10:306-317.

19. Moss-Racusin CA, Miller HG. "Taking charge" of stigma: Treatment seeking alleviates mental illness stigma targeting men. J Appl Soc Psychol. 2016;46:319335.

20. Emslie C, Ridge D, Ziebland S, Hunt K. Men's accounts of depression: Reconstructing or resisting hegemonic masculinity? Soc Sci Med. 2006;62:22462257.

21. Robertson $S$, Williams $B$, Oliffe $J$. The case for retaining a focus on "masculinities" in men's health research. Int J Mens Health. 2016;15:52-67

22. Beasley C. Rethinking Hegemonic Masculinity in a Globalizing World. Men Masculinities. 2008;11:86-103. 
23. Guillaumie L, Moisan J, Grégoire J-P, Villeneuve D, Beaucage C, Bordeleau L, Lauzier S. Contributions of community pharmacists to patients on antidepressants - a qualitative study among key informants. Int J Clin Pharm. 2017;39:686-696.

24. Guillaumie L, Ndayizigiye A, Beaucage C, Moisan, J. Grégoire J-P, Villeneuve D, Lauzier S. Patient perspectives on the role of community pharmacists for antidepressant treatment: A qualitative study. Can Pharm J (Ott). 2018;151:142148.

25. O'Reilly CL, Simon Bell J, Chen TF. Pharmacists' Beliefs About Treatments and Outcomes of Mental Disorders: A Mental Health Literacy Survey. Aust N Z J Psychiatry. 2010;44:1089-1096.

26. Boardman $H$, Lewis $M$, Croft $P$, Trinder $P$, Rajaratnam $G$. Use of community pharmacies: a population-based survey. J Public Health (oxf). 2005;27:254-262.

27. Granville G. "Racks of make-up and no spanners" an action research project into men's use of pharmacy to improve their health.

https://www.menshealthforum.org.uk/best-practice-men-and-pharmacies: Men's health forum. ; 2009. Accessed: 12.02.19

28. Chong WW, Aslani P, Chen TF. Pharmacist-patient communication on use of antidepressants: a simulated patient study in community pharmacy. Res Social Adm Pharm. 2014;10:419-437.

29. Guillaumie L, Moisan J, Grégoire J-P, et al. Perspective of community pharmacists on their practice with patients who have an antidepressant drug treatment: Findings from a focus group study. Res Social Adm Pharm. 2015;11:e43-e56.

30. Geffen ECv, Kruijtbosch M, Egberts AC, Heerdink ER, Hulten Rv. Patients' perceptions of information received at the start of selective serotonin-reuptake inhibitor treatment: implications for community pharmacy. Ann Pharmacother. 2009;43:642-649.

31. Chong WW, Aslani $P$, Chen TF. Adherence to antidepressant medications: an evaluation of community pharmacists' counseling practices. Patient Prefer Adherence 2013;7:813.

32. Murphy AL, Martin-Misener $R$, Kutcher SP, O'Reilly $C L$, Chen TF, Gardner DM. From personal crisis care to convenience shopping: an interpretive description of the experiences of people with mental illness and addictions in community pharmacies. BMC Health Serv Res. 2016;16:569-569.

33. Mey A, Knox K, Kelly F, et al. Trust and Safe Spaces: Mental Health Consumers' and Carers' Relationships with Community Pharmacy Staff. The Patient. 2013;6:281-289.

34. O'Reilly $C L$, Wong $E$, Chen TF. A feasibility study of community pharmacists performing depression screening services. Res Social Adm Pharm. 2015;11:364381.

35. Kondova A, Todorova A, Tsvetkova A, Arnaoudova M, Andreevska K, Grekova D. Screening and risk assessment for depression in community pharmacy-pilot study. J of IMAB. 2018;24:1928-1931.

36. Murphy AL, Martin-Misener R, Kutcher SP, O'Reilly $C L$, Chen TF, Gardner DM. From personal crisis care to convenience shopping: an interpretive description of the experiences of people with mental illness and addictions in community pharmacies. BMC Health Serv Res. 2016;16:569.

37. Knox K, Kelly F, Mey A, Hattingh L, Fowler JL, Wheeler AJ. Australian mental health consumers' and carers' experiences of community pharmacy service. Health Expect. 2015;18:2107-2120.

38. Readdean KC, Heuer AJ, Scott Parrott J. Effect of pharmacist intervention on improving antidepressant medication adherence and depression symptomology: A systematic review and meta-analysis. Res Social Adm Pharm. 2018;14:321-331.

39. Pirkis J, Schlichthorst $M$, King $K$, et al. Looking for the 'active ingredients' in a men's mental health promotion intervention. Adv Ment Health. 2018:1-11.

40. Wilkins $D$, Kemple $M$. Delivering male: effective practice in male mental health. London: Mind. https://www.mind.org.uk/media/273473/delivering-male.pdf 2010. Accessed 15.1.19. 
41. Cipriani A, Furukawa TA, Salanti G, et al. Comparative efficacy and acceptability of 21 antidepressant drugs for the acute treatment of adults with major depressive disorder: a systematic review and network meta-analysis. The Lancet. 2018;391:1357-1366.

42. Ho SC, Jacob SA, Tangiisuran B. Barriers and facilitators of adherence to antidepressants among outpatients with major depressive disorder: A qualitative study. PLoS One. 2017;12:e0179290.

43. British Medical Association, Royal Pharmaceutical Society. British National Formulary (BNF) 76: Pharmaceutical Press.

44. Lingam R, Scott J. Treatment non-adherence in affective disorders. Acta Psychiatr Scand. 2002;105:164-172.

45. Burton $\mathrm{C}$, Anderson N, Wilde $\mathrm{K}$, Simpson CR. Factors associated with duration of new antidepressant treatment: analysis of a large primary care database. $\mathrm{Br} \mathrm{J}$ Gen Pract. 2012;62:104-e112.

46. Woodward SC, Bereznicki BJ, Westbury JL, Bereznicki LRE. The effect of knowledge and expectations on adherence to and persistence with antidepressants. Patient prefer adherence. 2016;10:761.

47. Lasalvia A, Zoppei S, Van Bortel T, et al. Global pattern of experienced and anticipated discrimination reported by people with major depressive disorder: a cross-sectional survey. The Lancet. 2013;381:55-62.

48. Buus $N$, Johannessen $H$, Stage KB. Explanatory models of depression and treatment adherence to antidepressant medication: A qualitative interview study. Int J Nurs Stud. 2012;49:1220-1229.

49. Chong WW, Aslani $P$, Chen TF. Effectiveness of interventions to improve antidepressant medication adherence: a systematic review. Int J Clin Pract. 2011;65:954-975.

50. van Servellen G, Heise BA, Ellis R. Factors associated with antidepressant medication adherence and adherence-enhancement programmes: a systematic literature review. Ment Health Fam Med. 2011;8:255-271.

51. Read J, Cartwright C, Gibson $K$, Shiels C, Magliano L. Beliefs of people taking antidepressants about the causes of their own depression. J Affect Disord. 2015; 174:150-156.

52. Ridge $D$, Kokanovic R, Broom A, Kirkpatrick $S$, Anderson $C$, Tanner C. "My dirty little habit": Patient constructions of antidepressant use and the 'crisis' of legitimacy. Soc Sci Med. 2015;146:53-61.

53. Malpass $A$, Shaw $A$, Sharp $D$, et al. "Medication career" or "moral career"? The two sides of managing antidepressants: a meta-ethnography of patients' experience of antidepressants. Soc Sci Med. 2009;68:154-168.

54. Gibson K, Cartwright $C$, Read J. Conflict in Men's Experiences With Antidepressants. Am J Mens Health. 2018;12:104-116.

55. Spendelow JS. Men's self-reported coping strategies for depression: A systematic review of qualitative studies. Psychol Men Masculinity. 2015;16:439.

56. Johnson JL, Oliffe JL, Kelly MT, Galdas P, Ogrodniczuk JS. Men's discourses of help-seeking in the context of depression. Sociol Health IIIn. 2012;34:345-361.

57. O'Brien BC, Harris IB, Beckman TJ, Reed DA, Cook DA. Standards for Reporting Qualitative Research: A Synthesis of Recommendations. Acad Med. 2014;89:1245-1251.

58. Büchtemann $D$, Luppa $M$, Bramesfeld $A$, Riedel-Heller S. Incidence of late-life depression: A systematic review. J Affect Disord. 2012;142:172-179.

59. Malterud $K$, Siersma VD, Guassora AD. Sample Size in Qualitative Interview Studies: Guided by Information Power. Qual Health Res. 2016;26:1753-1760.

60. Braun V, Clarke V. Using thematic analysis in psychology. Qual Res Psychol. 2006;3:77-101.

61. Ziebland $S$, McPherson A. Making sense of qualitative data analysis: an introduction with illustrations from DIPEx (personal experiences of health and illness). Med Educ. 2006;40:405-414.

62. Government Digital Service. Ethnicity Fact and Figures; List of Ethnic Groups https://www.ethnicity-facts-figures.service.gov.uk/ethnic-groups. 2019. Acessed 12.10.19 
63. Anderson C, Kirkpatrick S, Ridge D, Kokanovic R, Tanner C. Starting antidepressant use: a qualitative synthesis of UK and Australian data. BMJ Open. 2015; 5:e008636.

64. Nederlof M, Cath DC, Stoker LJ, Egberts TCG, Heerdink ER. Guidance by physicians and pharmacists during antidepressant therapy: patients' needs and suggestions for improvement. BMC Psychiatry. 2017;17:388.

65. Hindmarch T, Hotopf M, Owen GS. Depression and decision-making capacity for treatment or research: a systematic review. BMC Med Ethics. 2013;14:54.

66. Rochlen $A B$, Paterniti DA, Epstein RM, Duberstein P, Willeford L, Kravitz RL. Barriers in diagnosing and treating men with depression: a focus group report. Am J Mens Health. 2010;4:167-175.

67. Rennick-Egglestone S, Knowles S, Toms G, Bee P, Lovell K, Bower P. Health Technologies 'In the Wild': Experiences of Engagement with Computerised CBT. CHI 2016. ACM; 2016:2124-2135.

68. Ridge $D$, Emslie $C$, White $A$. Understanding how men experience, express and cope with mental distress: where next? Sociol Health Illn. 2011;33:145-159.

69. Emslie C, Ridge D, Ziebland S, Hunt K. Exploring men's and women's experiences of depression and engagement with health professionals: more similarities than differences? A qualitative interview study. BMC Fam Pract. 2007;8:43.

70. Chakraborty K, Avasthi A, Kumar S, Grover S. Attitudes and beliefs of patients of first episode depression towards antidepressants and their adherence to treatment. Soc Psychiatry Psychiatr Epidemiol. 2009;44:482-488.

71. Latalova K, Kamaradova $D$, Prasko J. Perspectives on perceived stigma and selfstigma in adult male patients with depression. Neuropsychiatr Dis Treat. 2014; $10: 1399$.

72. Maund $E$, Dewar-Haggart $R$, Williams $S$, et al. Barriers and facilitators to discontinuing antidepressant use: A systematic review and thematic synthesis. $J$ Affect Disord. 2019;245:38-62.

73. Hindi AMK, Jacobs S, Schafheutle EI. Solidarity or dissonance? A systematic review of pharmacist and GP views on community pharmacy services in the UK. Health Soc Care Community. 2019;27:565-598.

74. Dey RM, de Vries MJW, Bosnic-Anticevich S. Collaboration in chronic care: unpacking the relationship of pharmacists and general medical practitioners in primary care. Int J Pharm Pract. 2011;19:21-29.

75. El-Awaisi A, Joseph S, El Hajj MS, Diack L. A comprehensive systematic review of pharmacy perspectives on interprofessional education and collaborative practice. Res Social Adm Pharm. 2018;14:863-882.

76. Scahill S, Fowler JL, Hattingh HL, Kelly F, Wheeler AJ. Mapping the terrain: A conceptual schema for a mental health medication support service in community pharmacy. SAGE Open Med. 2015;3.

77. Hung C-I. Factors predicting adherence to antidepressant treatment. Curr opin psychiatry. 2014;27:344-349.

78. Jose J, AlHajri L. Potential negative impact of informing patients about medication side effects: a systematic review. Int J Clin Pharm. 2018;40:806-822.

79. Santina $T$, Lauzier $S$, Gagnon $H$, et al. The Development of a Community Pharmacy-Based Intervention to Optimize Patients' Use of and Experience with Antidepressants: A Step-by-Step Demonstration of the Intervention Mapping Process. Pharmacy (Basel). 2018;6:39.

80. Hattingh HL, Scahill S, Fowler JL, Wheeler AJ. Exploring an increased role for Australian community pharmacy in mental health professional service delivery: evaluation of the literature. J Ment Health. 2016;25:550-559.

81. Fava GA, Gatti A, Belaise C, Guidi J, Offidani E. Withdrawal Symptoms after Selective Serotonin Reuptake Inhibitor Discontinuation: A Systematic Review. Psychother Psychosom. 2015;84:72-81.

82. Aikens JE, Nease DE, Nau DP, Klinkman MS, Schwenk TL. Adherence to maintenance-phase antidepressant medication as a function of patient beliefs about medication. Ann Fam Med. 2005;3:23-30. 
83. Knox K, Fejzic J, Mey A, et al. Mental health consumer and caregiver perceptions of stigma in Australian community pharmacies. Int J Soc Psychiatry. 2014;60:533-543.

84. Knox K, Hattingh L, Wheeler AJ. Community pharmacy staff motivations and barriers to working with mental health consumers. J Pharm Pract Res. 2016;46:245-252.

85. Liekens $S$, Vandael $E$, Roter $D$, et al. Impact of training on pharmacists' counseling of patients starting antidepressant therapy. Patient Educ Couns. 2014;94:110-115.

86. Scheerder G, De Coster I, Van Audenhove C. Pharmacists' role in depression care: a survey of attitudes, current practices, and barriers. Psychiatr Serv. 2008;59:1155-1160.

87. Rickles NM, Dube GL, McCarter A, Olshan JS. Relationship between attitudes toward mental illness and provision of pharmacy services. J Am Pharm Assoc. 2010;50:704-71 
